\title{
Possibilities and Challenges of Teaching Reading in a Multi-Grade Classroom
}

\author{
Masello Phajane \\ Department of Early Childhood Education (ECE), University of South Africa (UNISA), \\ PO Box 392 Pretoria 0003 \\ Email: phajamh@unisa.ac.za
}

\section{Doi:10.5901/mjss.2014.v5n15p359}

\begin{abstract}
In South Africa instruction frequently occurs in multi-grade settings where, due to lack of teachers and space, two to three teachers teach six classes. Many teachers lack the knowledge and skills to manage multi-grade classes effectively as they have been trained for single-grade teaching. A qualitative research design was chosen for this study because the methodology best allowed the collection of data to answer the research question, namely What are possibilities and challenges of teaching reading in a multi-grade classroom? A case study was used for this study. Yin (2003: 1) states that "case studies are the preferred strategy when 'how or 'why' questions are being posed, when the investigator has little control over events, and when the focus is on a contemporary phenomenon within some real life context". This descriptive and interpretive study took place within a bounded context; it focused on possibilities and challenges of teaching reading in a multi-grade classroom? Based on the findings of the study, this paper argues that multi-grade strategies and techniques received from observation and interviews have positive impact upon the teaching and learning practices of the school. However, government has to play a key role in sustaining the implementation and impact of multi-grade course strategies and techniques.
\end{abstract}

\section{Introduction}

The multi-grade class structure is known by various names as composite, combination classes, double classes, split classes, mixed- age classes and vertically- grouped classes Veenman, (1995:32). It is defined as a class in which students of two or more adjacent grade levels are taught in the one classroom by one teacher for most if not all of the day. Mason and Burns, (1996:25) Veenman, (1995:48). Usually a multi-grade split -grade or combination of grades include children from more than one grade level. Vincent, (1999:42). The reasons for the existence of multi-age classes exist reflect either a philosophy or an administrative consideration.

As the philosophical reason the students benefit from the range and diversity possible with multi-age grouping, which reflects a deliberate and systematic mixing of students of different ages as desirable and as beneficial to students; the second reason for the existence of what are usually defined as multi-grade classes is more mundane, far more common. The classes are combined because there is simply not enough number of students to form a single-grade class, or due to schools isolation. By combining grades, small rural schools can continue to exist within a, more cohesive and viable community. Nylor, 2000:23). The multi-grade classes form, exclusivement in rural where the community is small, but multi-age classes can form deliberately anywhere. Boysee, (2002:25).

Multi grade classrooms and schools naturally occur in the remotest, most sparsely inhabited and least accessible areas in the country (South Africa). This means the circumstances that give rise to multi grade classrooms reinforce the conditions that exist in these schools. Some farm schools have no electricity, running water or ablution facilities, there might be a chalk board, but this could be pitted and scarred from years of use. The buildings might be, at best, stark and simple; while at worst they might be dilapidated. Classroom furniture could well be inadequate in number, rickety or even unsafe. Adding to these problems are issues of communication: some farm schools have no telephone, fax or even postal deliveries. The teacher might have to travel some distance to collect mail, circulars and so on. Remoteness means that support visits from the education department seldom occur and distance also hinders teachers from joining in with peer support initiatives, such as the Brits department of education's peer working group's model.

So where does this leave the beleaguered teacher of a multi grade class? Is the answer a "magic bullet" of resources suddenly directed at multi grade schools, which are likely to be in the lowest quintile? Realistically, we all know that there is such a resourceful backlog that this is improbable. The onus must, therefore, fall on to the shoulders of the teacher. This sounds daunting, but unless the teacher develops a "can do" attitude and a problem-solving, professional approach that puts the welfare and development of the learner at the centre, the challenges of the multi grade classroom 
could be overwhelming.

Many people get a negative feeling when they hear the word multi-grade. They connect 'not enough students, money and resources" with multi-grade classes. These reasons don't give a good impression for a child's education. Some research supports the negative vision of multi-grade. Masons and Burns (1996:42) argues that while multi-grade classes are good for some students, they are 'potentially onerous' for most, and increase teacher stress. Their case is not that teachers in such classes are inferior, but that the demanding nature of multi-grade teaching reduces the quality of instruction.

On the other hand, there are also researchers that have arguments in favour of multi-grade. They argue that the students benefit from the various ages and diversity of ability in multi-grade classes. Gaustad (1997:35) argued that "Research indicates that heterogeneous grouping promotes cognitive and social growth, reduces ant-social behaviour, and facilitates the use of research-based developmentally appropriate instructional practices such as active learning and integrated curriculum".

These people who stand behind multi-grade classes deliberately group their students into multi-grade classes. They don't group their students not because they don't have a choice, but because they want to. How can it be that there are so many different opinions about multi-grade? The difference must lay in the way you implement multi-grade classes. The main question is, "What are possibilities and challenges of teaching reading in a multi-grade classroom? This is the question that this article deals with.

There can be a misperception on what multi-grade is. Multi-grade is generally taken to be a set of techniques that allow a teacher to deliver effective instruction to groups of pupils of various ages and capabilities (Miller: 1989). Some people think that multi-age and multi-grade is the same thing. Although they are not the same they do have similarities:

- Both multi-grade and multi-age refer to classroom situations where children of two or more grade levels are grouped together for educational purposes.

- The age range of the children in both types of the classroom will be greater than one year.

- Students remain in the same classroom with the same teacher for more than one year.

- In multi-grade and multi-age classroom there will be a wider range of individual differences than one would find in a single grade classroom (Mulcahy, 2000:33)

There is still a big difference between the two. Multi-grade classes are graded and multi-age intends to be nongraded. In multi-ages they try to eliminate grade-levels so that each student can develop on their own developmental level. This helps students not to feel like failures when they need an extra year.

Multi-grade classroom are two or more grades put together in one class, but each grade still has its own curricula. This can be unreasonable task for the teacher and a lot of things can go wrong in a multi-grade class.

These are the challenges they experienced in a multi-grade class. It can be a time wasting situation for the learners if the teacher is not organised and well prepared. Teachers have to prepare activities for all the different levels in the class and it could easily happen that the work is too hard for the weak learners and too easy for the strong learners. Students may receive less individual attention and must often work independently.

Multi-grade classes force teachers and learners to use alternative teaching and learning approaches, breaking the tradition of the rote memorization and repetition. The strategies and techniques used in the multi-grade classes have to keep these problems and factors that can occur, in mind. Miller (1989:42) identifies six areas essential for multi-grade instruction. The examples in each area are of the strategies and techniques from observation and interviews.

\section{Research Methodology}

The study was a qualitative study which consisted of interviews and observations. Purposive sampling was used to select 1 teacher teaching in a multi-grade classroom of a Foundation Phase School in Brits District of North West Province in South Africa. The participant was interviewed for a minimum of 30 minutes at the beginning of the study. The researcher used semi-structured questions for the candidate. Apart from the in-depth interviews the researcher observed at least two lessons for the participant. In each observation the researcher was a non-participant observer. During observations the researcher used an observation schedule to guide his observations. Aspects looked into by the researcher included the following:

* The use of critical thinking in lesson delivery;

* Proof of critical reflection in lesson planning;

* The kind of activities that the teacher promotes in a multi-grade classroom;

* The roles of the teacher and the learners in the classroom; and 
Looking at forms of assessment the teacher uses.

\section{Instructional Delivery and Grouping}

The teacher used all different methods to deliver the instruction to the class. Various ways of instruction keep it interesting for the students. Sometimes it is necessary to write some instruction on the board. Students in the younger grades just love it, because they feel proud if they can carry out the instructions simple by reading it from the board. Writing instructions on the chalkboard can also be a handy tool for grouping the students in different ways, because above the instruction one is able to write who the instruction meant for. Students can be grouped in different ways depending on what the teacher wants to achieve with the activities. Students can be grouped according to the following criteria's: same abilities together, strong and weak together, confident learners' together and other ways around and grades together.

\section{Self Direct Learning}

The teacher's time has to be divided between different grades and that means that the learners need to work independently while the teacher is busy with the other grade. Some ways to make sure that the students do their work is to give the learners work plans. A work plan is a list of activities the learners have to do and finish off at their own rate and time. This work plan can stretch over a few subjects. In some cases the students have access to materials to be productive on their own. It is then useful for a class to have a library, some self-teaching guides and already prepared exercises by the teacher.

\section{Planning and Using Peer Tutoring}

Peer tutoring benefits both tutors and learners, and serves as a powerful tool for extending the influence of the teacher in the classroom. Some examples on how it can be used; there is a rule in the class that when a grade one student is unable to write a word, they ask a grade two student to help them. Both benefit from this because the grade two students can revise his word and the grade one student can learn how to spell the word. Reading is vital part of a grade one daily program. Buddy reading is implemented, seeing that it is an unreasonable task for the teacher to listen to each grade one student. This involves grouping each grade one student with a grade two student. Strong grade one students are grouped with weak grade two students and vice versa. In this way she can make sure that each grade one student practices their reading every day. Another peer tutoring technique is to let them check their own work. This can be lead by one of the "bright" students in that grade. When they re finished the teacher can help with any problems.

\section{Classroom Management and Discipline}

An essential part of multi-grade classes is that the teacher establishes a routine, so that the learners feel secure and know what is to be expected of them. The teacher should have a sign or noise which implies that the students have to listen at that time and stop doing their work; this is because it could become an unreasonable task to get everybody's attention if there are a lot of activities going on in the classroom. The teacher should be strict, so that the learners know that she means it when she says that they have to work quietly and not interrupt her if she is busy with another group. Otherwise it will become an obstacle for multi-graded classes working effectively. A thing that can help with classroom management is that the learners can reflect on how the lesson or activity went, in that way the teacher can improve the organization and management, so that it is the best for all students. In some activities it can be handy to ask a mother or teacher assistant to come in and help to make the most of the activity.

\section{Classroom Organization}

A characteristic of a multi-grade class is that different activities happen at the same time. In that way it is essential to provide semi-private spaces, like a reading corner, another for science and geography for groups of students to work. A working space outside the classroom, with a chalkboard and tables and chairs can also be handy, because some multigrade classes just don't have enough space. A chalkboard on the opposite wall also permits the teacher flexibility in arranging and moving different groups around. That's why it is handy for a multi-grade class t have furniture that can be easily moved, because the teacher can, for example, ask one group of students to turn their desk to the chalkboard at the 
back of the classroom, so that there is less interruption for the rest of the class and they can do their own work. The flexibility of the desk can also help for grouping students in different ways and the desks can form a larger working space.

\section{Instructional Organization and Curriculum}

Two curriculums that have to be followed, to make it easier for the teacher is to compare the curriculums before hand and prepare the lessons so that some themes you can do with both grades and them implement different levels of thinking and activities. This allows for challenging work for all different abilities. A handy way to keep some students of different levels busy is to ask the student with more abilities to explain the work to the student with less ability. In that way the learner with more ability uses higher order thinking to explain what is going on in his mind in his own words. It is actually an advantage to have two grades in one class, because students that develop faster can easily be accommodated with the activities of the higher grade so that the student is not kept back.

A lot of strategies and techniques are discussed, but does it help to improve the effectiveness of the multi-grade classroom? Feldman and Gray (1999:40), found four benefits for implementing some of the strategies and techniques:

1. Younger children actively use older children to develop skills and to acquire knowledge.

2. Mixed-age play offers unique opportunities for creativity and the practice of skills

3. Age mixing provides opportunities for children to find others of matching abilities.

4. Older children actively assert responsibility for younger ones and develop an increasingly sophisticated understanding of that responsibility.

\section{Findings}

Based on the analysis of collected data, the findings are discussed under six major themes namely: classroom factors impacting teaching reading, classroom and lesson activities, classroom displays, teacher learner interactions, the classroom size, learning environment.

\section{Classroom Factors Impacting Teaching Reading}

According to Au (2003:44), different methods can be used to achieve the same outcome; Teacher Masego used the combined approach to present her lesson, which not only focuses on one approach to the teaching of reading. She used a combination of methods in order to make the mastery of the reading skill easier for the learners, namely the phonics instruction, phonological awareness, making a word and an alphabetic principle blending in one reading lesson. As the new Curriculum (CAPS) evolved, The DoE (2001:274) realised the need for greater emphasis on basic skills being taught to learners, especially in the formative years. The curriculum has revolutionised teaching and learning by centring the teacher's focus on the holistic development of the learner. Once learners leave the Foundation Phase they are expected to be equipped with the average reading, writing and counting skills.

Children in Katlego School, due to overcrowding, were still seated in rows or church style, facing one direction. However, Teacher Masego used different teaching methods (i.e. combined or mixed methods). From what the researcher observed, the way the teacher arranged her classroom did not mean learners work cooperatively together. For them to be active agents, as in line with $\mathrm{Au}(2003: 48)$ and the DoE (2001:284), all learners need to be taught strategies to help them read with understanding, and to help them unlock the code of the read words. Teachers could thus consider including different approaches when teaching beginning reading to beginners.

\section{Classroom Display}

While entering the same classrooms at the post intervention stage, classrooms were found artistically decorated with the tasks of students. Displaying the tasks of students had been a challenge for teachers as they used to complain about the space to display learners' tasks. The teachers had thought of creative ways to display such tasks now. Such displays have tremendous impact upon the interest and motivation of students. They refer to the specific displays and claim their ownership. The same displays were used to review previous lessons taught in the classroom.

\section{Teacher Learner Interactions}

According to Burns (1999:17), where two or more Grades are put together in one classroom because there are too many 
students and too little space, it is called a 'multi-grade class'. In the beginning, Teacher Masego at Katlego School combined Grades 1 and 2 sit on the floor facing the board and explored aspects of the same theme i.e. conducted a lesson on reading with both groups. There was no reason to separate learners at this stage for reading, as they all should have been able to read the same text. She introduced reading by narrating a story about a monkey which was tied by a rope to a tree, after which the teacher started with the basics. Firstly, the learners were supposed to recognise and read all the letters of the alphabet, and they should also be able to know the sounds associated with each other.

The learners were introduced to the formation of each letter in the following ways: the teacher showed the formation on the chalkboard, then in the air, taking care when facing the learners that the letter was formed in the correct way around for them. The learners watched and then imitated, saying the sound, they did this several times. Teacher Masego built vocabulary by writing a few words on the chalkboard each day that may occur in stories and referred to them several times a day so that learners became familiar with the spelling and the sound.

Reinforcement of the letter sound was very important. It was vital that the learners knew the letter sounds, as they needed to be fluent in saying the sound immediately after having seen the letters. However, learning the letter sound is not enough. The learners needed to know how to apply their letter knowledge. From the beginning they were taught to blend the sounds and hear the words for reading, as well as learning that the words they spoke could also be written. Language is made up of separate pieces and words are the most important of these.

She explained the class or lesson activity to the children as follows: she wrote the words from the list on the chalkboard, called a learner to the front of the class and asked him or her to find and identify a specific word. When the learner had found the word the class read it aloud together and wrote it in the air with their fingers. She then divided the class into groups, Grade 1 and Grade 2. The Grade 1 challenged the Grade 2 to write a specific word from the wordlist on the chalkboard. If a learner from Grade 2 spelled the word correctly by him/herself then the group won three points. If the learner had to seek help from the rest of the Grade, then it received only two points. If nobody in the group knew how to spell the word, then Grade 1 received a bonus point. Grade 2 would then ask a representative from Grade 1 to write a new word from the word list on the chalkboard.

This competition could last for a week, after which new words could be formed with different learners. Each day the teacher dictated some words for the Grades 1s and sentences for grade 2's to write in their exercise books. She then prepared weekly spelling and reading tests for all the learners. She divided the time between the two Grades, and learners worked independently while she was busy with the other Grade. She gave them a work plan, which was a list of activities they had to do and finish off at their own pace and in their own time.

\section{Classroom and Lesson Activities}

For the Grade 1's activity Teacher Masego used six groups of ten children, two of which were made up of transfer learners new to the school. These learners were clearly behind and struggled to understand, speak or write Northern Sotho. They had apparently not attended Grade R, a difference of levels that often challenge the teacher and makes her tasks more difficult. However, separating those learners from others would only perpetuate the problem, whereas including them in other groups is more likely to succeed. Learners were asked to trace the outline of the vowels and consonants twice into their worksheets.

For continuation of the activity, children were also given magazines from which to cut out the letters (vowels) and consonants, then trace them on their worksheet and paste them into their workbooks. Most of the groups had a pair of scissors and glue. Teacher Masego did some concept checking to make sure those learners understood the meaning of 'same' and 'different'. Working in groups, learners were asked to look at two vowels and consonants (language) in the workbook and to identify three "similarities" (uuu, nnn, bbb, ddd) and three "differences", (un, bd, ft). In each case the whole group was asked to come up to the front and report back, which they did by chanting their answers in unison.

She then introduced learners to a book before leaving them to read it, discussed the character they meet and the background against which the story was set so the learner had 'hooks' on which to hang meaning when reading. Learners were grouped into groups of six, and introduced to the characters they were reading about. The pictures of the characters were displayed and discussed. Learners coloured in pictures and talked about each character. The names of the characters were flashed and displayed in the classroom. Flashcards with words in the story to follow were given to each child to learn as homework. Picture books showing the characters were discussed by the teacher and with learners in a group, thus making them familiar with the stories to come. Words were flashed up and the teacher tested learners on those words for reading.

Learners must be taught the left-to-right eye movement, and at the beginning teachers ensure that the child points out the words as they read. This prevents the learner from learning the story off by heart and encourages word 
recognition. She reads the story, and then the children follow and read individually. Once the story is read, a discussion should follow to ascertain whether learners have comprehended what has been read. Reading should not only be done from books. Charts should be read out and instructions on worksheets should be read. Signs in the classroom and the school must be read so that they become meaningful for the learners. She took turns when reading with her learners, then they read to her and she back to them.

The activity for the Grade 2 lesson was on sentence building. Teacher Masego modelled a sentence on the chalkboard with the key words as subject from the story. She then asked learners, working in groups, to generate sentences containing the key words. However, she offered no explanation as to why they were using the key words from the story they had read, and not those of their choice. By doing this she was not able to make connection between this outcome and what she should be looking for when assessing the performance of her learners. When the researcher asked her what she saw as the outcome of the lesson she struggled to tell her. Although the learners were very engaged with the task, they were given no idea about how long they had to complete it and by what criteria they would be assessed.

Secondly, there is a missed conception that CAPS and Group work are synonymous. This leads to the notion that, if learners are participating actively in a group work activity and doing constant report backs, they are doing CAPS. The teacher appears to struggle to identify meaningful purposes of group work and to link these to the overall outcome(s) of the lesson. Perhaps the hardest nut to crack is the lack of content knowledge that teacher displays. C2005 has done a disservice to the art of teaching reading to the First Grades by underplaying the importance of content in the curriculum and content knowledge in teachers who deliver curriculum.

She then asked the groups to report back their sentences. Most sentences reinforced traditional gender roles "mosetsana o fiela lebala", (the girl sweeps the yard) "mosadi o kga metsi", (the woman fetches water). In conclusion, she introduced different types of sentences, short and long, and asked them to write theirs.

The five benefits of a multi-grade classroom that impressed the researcher when observing the teacher-learner interaction of teaching reading were as follows: younger learners (Grade 1) actively used the older learners (Grade 2) to develop reading skills and to acquire the knowledge; mixed-age play, offered unique opportunities for creativity and the practice of reading skills; age mixing provided opportunities for learners to find others of matching abilities; older learners actively asserted responsibility for younger ones and develop an increasingly sophisticated understanding of that responsibility; lastly, it is an advantage to have two grades in one class, because learners who develop faster can easily be accommodated with the activities of the higher grade so that learners are not kept back.

\section{The Classroom Size}

Katlego Primary School had five rooms, four classrooms and a room for meetings, while other classes were held under trees and in makeshift shacks. It had a combination of Grades 1 and 2, Grades 3 and 4, and a Grade 5 and 6, which according to Miller (2002:32) is a multi-grade classroom. In a combined classroom of Grade 1 and 2, 120 learners were crammed into one classroom that had been designed for 35 learners. Learners from Grades 1 and 2 shared a classroom, which was also used as the teacher's staffroom, administration office and storeroom. In these classrooms the difficult Grades were taught alternatively, i.e., Grade 5 in the first period and Grade 6 in the second, with one Grade sitting outside and waiting patiently for the other to finish its lesson. It was difficult for learners to focus on their teacher, especially when other grades were having free periods. This also placed unreasonable expectations on the teacher.

Generally, learners in all schools (classrooms) were arranged or seated in church-style facing one direction. From the classroom observation learners did not work cooperatively together, the teacher giving the same tasks for all the learners whereby each worked out his or her activity (individual activity). In this case, teachers should encourage learners to work together and create a flexible learning environment, by giving different tasks, as learners are not all learning at the same pace.

\section{Learning Environment}

The shortage of classrooms and resources at Katlego Primary School, inconvenienced teachers and made their work unbearably and frustrating. This school accommodated learners from Grades one to Six. The majority of the learners resided in the surrounding area and some learners were from the surrounding informal settlements (Chris Hani, Joe Slovo, Walter Sisulu and Mandela village), which was the result of political violence that had disrupted schools in 1993. The school was located in the area that had experienced the least violence. This situation may have contributed to deterioration in the standard of teaching reading, because most of the learners came from multicultural families and were 
speaking different languages, such as Venda, Zulu, Xhosa, Xitsonga, Sepedi, Sesotho and Setswana, which was seen as a barrier to learning, especially in the Grade 1 classes. Due to the pressures engendered by the (physical) learning environment context, the teacher may not have time to process and think clearly about learners or be able to help them all reach their optimal capability of reading. This in turn may affect the way she structured teaching reading for them.

\section{Conclusion}

This article has shown that students can benefit from multi-grade programs when they are properly implemented. Such programs offer unique opportunities for increased achievement and improved socialization pattern. More importantly, multi-grade techniques foster skills in self-learning which benefit the student throughout his or her life. Multi-grade programs however, require special efforts to implement. So it is a vital thing for a multi-grade teacher to have training that give teachers the skills they need to effectively manage a complex classroom environment.

\section{References}

Ames, P. (2006). A multi-grade approach to literacy in the Amazon, Peru. In A. W. Little (Ed.), Education for all multi-grade teaching: Challenges and opportunities, (pp.47-66), Netherlands: Springer.

Berry, C. \& Little, A. W. (2006).Multi-grade teaching in London, England. In A. W. Little (Ed.), Education for all multi-grade teaching: Challenges and opportunities, (pp.67-86), Netherlands: Springer.

Birch, I. \&Lally, M. (1995).Multi-grade teaching in primary school. Thailand: UNESCO.

Hargreaves, E. (2001). Assessment for learning in the multi-grade classroom. International Journal of Teacher Development, 21, 553560.

Khan, J. W. (2006).School improvement in Multi-grade situation (SIMS): An innovation of the PDCC. Paper presented at the International Conference on Quality in Education: Teaching and leadership in challenging times sponsored by Aga Khan University, Karachi, Pakistan.

Little, A. W. (2006). Education for all: Multi-grade realities and histories. In A. W. Little (Ed.), Education for all multi-grade teaching: Challenges and opportunities, (pp.1-26), Netherlands: Springer.

White, S. \& Reid, J. (2008). Placing teachers? Sustaining rural schooling through place-consciousness in Teacher Education. Journal of Research in Rural Education, 23(7), 1-11. 